\title{
Dr. Sun's Procedure for Type A Aortic Dissection: Total Arch Replacement Using Tetrafurcate Graft With Stented Elephant Trunk Implantation
}

\author{
Wei-Guo Ma, Jun Zheng, Yong-Min Liu, Jun-Ming Zhu, Li-Zhong Sun* \\ Department of Cardiovascular Surgery, Beijing Anzhen Hospital, Beijing Aortic Disease Center, Capital Medical University, Beijing, China
}

\begin{abstract}
Sun's procedure is a modified elephant trunk technique that integrates the advantages of open surgical and endovascular repairs as a treatment of type $A$ aortic dissection. It is named after Dr. Li-Zhong Sun and refers to total arch replacement using a four-branched graft with implantation of a special stented endovascular graft. Since its introduction, it has produced excellent early and late clinical outcomes. We present a video of this procedure and make an overview regarding the technical aspects, surgical indications, and clinical outcomes of Sun's procedure.

Copyright $\odot 2013$ Science International Corp.
\end{abstract}

Key Words

Aorta - Dissection - Stent · Graft · Surgery

\section{Introduction}

Acute type A aortic dissection remains the most common of all aortic catastrophes and is associated with significant morbidity and mortality [1], and the timehonored dictum is that urgent surgery should be undertaken [2]. In 1983, Borst introduced the elephant trunk procedure [3], followed by a variety of modifications [4-6], with improved clinical outcomes over the years [7-9]. Recently, endovascular placement of stent grafts and hybrid repair have also emerged as new treatment options $[10,11]$. An ideal therapy should be able to replace the dissected aortic segment as long as possible and obliterate the false lumen, which is essential to minimizing operative risks and avoiding or reducing the need for reinterventions.

In our practice, we have been trying to find a new treatment option that integrates the advantages of open surgical and endovascular repairs. In 2002, the senior author (L.Z.S.), then the chief of Aortic Surgery in Fu Wai Hospital, designed a new stented graft and proposed a modified technique of total arch replacement using a four-branched graft with implantation of this stented elephant trunk as a treatment for type $A$ aortic dissection [12], which has produced satisfactory early and long-term results [13-17]. Owing to its ingenious design, widespread usage, and excellent outcomes, this technique was named after Dr. Sun by domestic and international colleagues in 2008, hence the term "Sun's procedure," i.e., total arch replacement using a tetrafurcate graft with stented elephant trunk implantation [18]. In this paper, we briefly describe Sun's procedure with regard to operative techniques, surgical indications, and clinical outcomes. A video showing the technical details can be accessed at http://dx.doi.org/ 10.12945/j.aorta.2013.13.015.vid.01, for better understanding of the Sun's procedure.

\footnotetext{
*Corresponding author:

Li-Zhong Sun

Department of Cardiovascular Surgery

Beijing Anzhen Hospital

Beijing Aortic Disease Center

Capital Medical University

2 Anzhen Road

Beijing 100029, China

Tel. +86 106445 6168, E-Mail: lizhongsun@outlook.com
} 


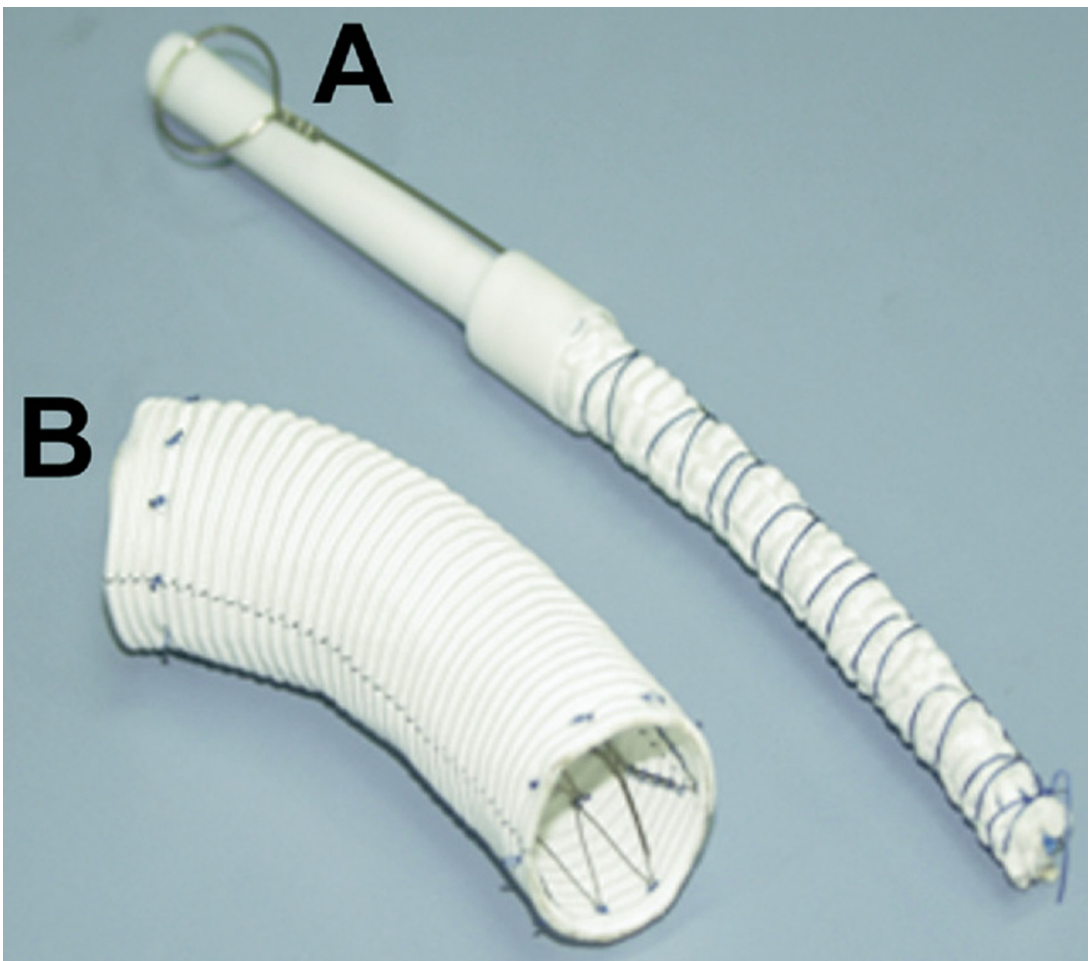

Figure 1. The stented elephant trunk, Cronus ${ }^{\circledR}$, before $(A)$ and after (B) implantation.

\section{Surgical Techniques}

Sun's procedure encompasses several technical details in terms of cannulation, cardiopulmonary bypass, cerebral protection, and surgical skills [12-16]. It is performed via a median sternotomy under total cardiopulmonary bypass (CPB) and selective cerebral perfusion (SCP) with cannulation of the right axillary artery (RAA). The arterial line is bifurcated for perfusing the brain through RAA and the descending, abdominal aorta and lower extremities through one branch of the tetrafurcate graft [12]. If indicated, root procedures are finished during cooling. Circulatory arrest is instituted as the nasopharyngeal temperature reaches $25^{\circ} \mathrm{C}$. After the arch vessels are cross-clamped, antegrade SCP through RAA is started. The ascending aorta and transverse arch are opened, and the three arch vessels are transected at their origins from the arch. A stent endograft (Cronus ${ }^{\circledast}$, Shanghai MicroPort Medical, China) (Fig. 1) is inserted into the true lumen of the descending aorta and deployed to compress the false lumen and, most importantly, to enlarge the true lumen. Then the stented endograft is anastomosed to a four-branched graft (Maquet Cardiovascular, Wayne, NJ) end-to-end. All anastomoses are completed with continuous 4-0 prolene suture without pledgets. The suture line should include the endograft, the native aorta, and the tetrafurcated graft so that all these structures are joined firmly together (Fig. 2). When the distal anastomosis is completed, perfusion of the lower body is resumed through one branch of the tetrafurcate graft, and the CPB flow is gradually returned to $2.0-2.4 \mathrm{~L} / \mathrm{m}^{2} / \mathrm{min}$.

To minimize the time of cerebral and cardiac ischemia, the left common carotid artery is reconstructed first. On completion of anastomosis, rewarming begins, and SCP is continued through the RAA and left common carotid artery. Then, continuity between the tetrafurcate graft and the distal ascending aorta is established. The ascending aorta is declamped and heart beat returns. Finally, the left subclavian and innominate arteries are, in turn, anastomosed to the four-branched graft end-to-end (Fig. 2).

Difficulties may occur during the dissection and immobilization of the left subclavian artery. Great caution must be taken when suturing the distal anastomosis, because bleeding at this site may be very difficult to control afterward.

The core technique of Sun's procedure lies in its unique stented graft, which has the following advantages. First, it can be deployed very quickly, often within seconds, which decreases the technical diffi- 


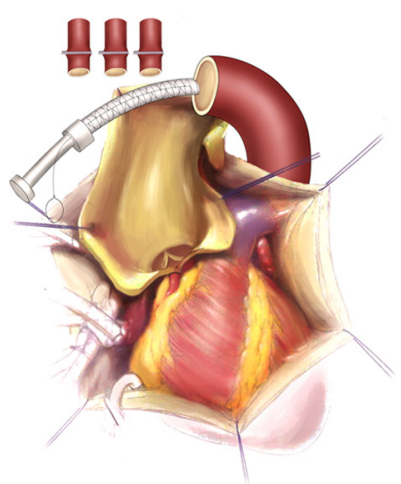

A

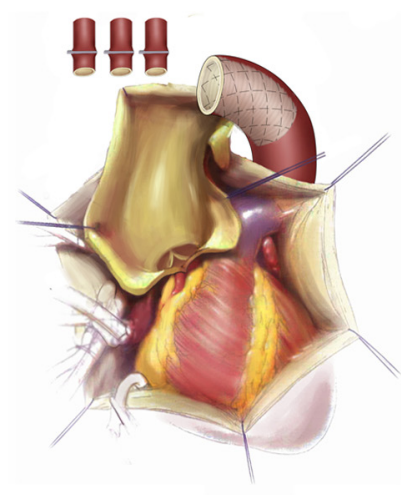

B

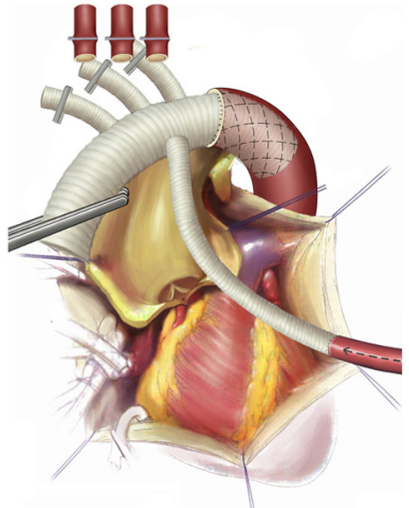

C

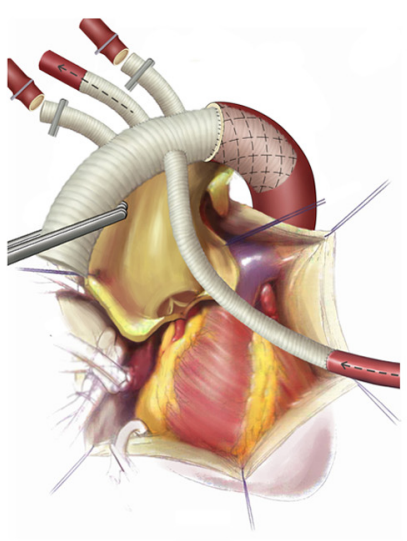

D

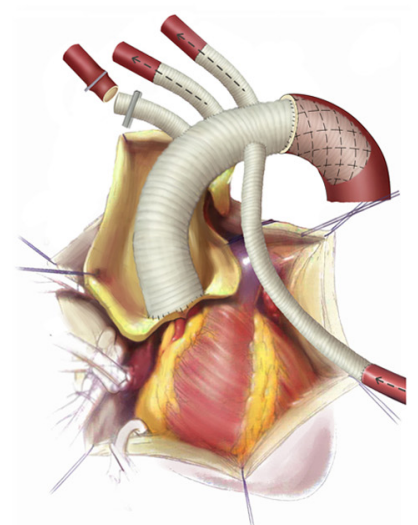

F

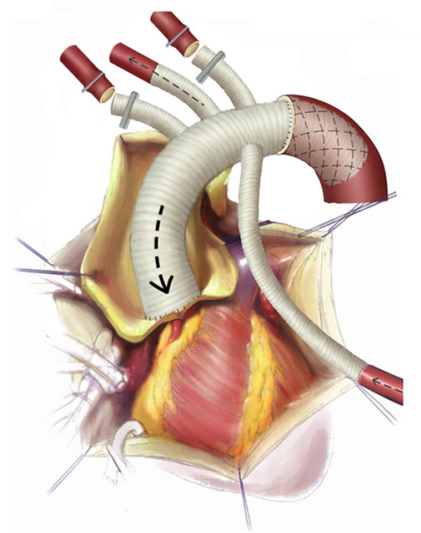

E

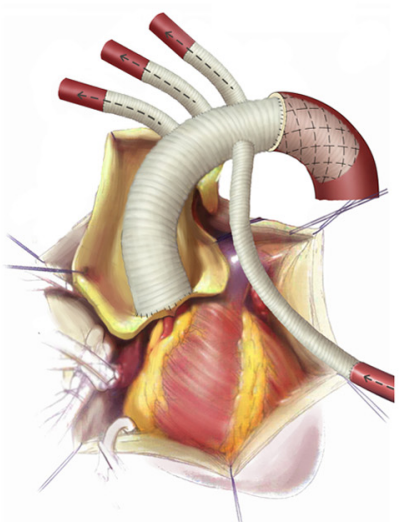

G

Figure 2. Schema of Sun's procedure. (A) Insertion of the stented elephant trunk into the descending aorta; (B) Deployment of the stented elephant trunk in the descending aorta; (C) Anastomosis of four-branched graft distally to stented elephant trunk and perfusion of descending aorta restarted; the suture line should include the endograft, native aorta, and tetrafurcated graft, joining all three layers firmly together; (D) Reconstruction of left common carotid artery, SCP continued through RAA and left common carotid artery, and rewarming begins; (E) Anastomosis of four-branched graft proximally to ascending aorta and perfusion to the heart resumed; (F) Reconstruction of the left subclavian artery; (G) Reconstruction of the innominate artery. 
culty and makes the implantation easier, compared with delivery in endovascular and other open repairs. Second, this stented endograft has an extra centimeter of attached regular vascular graft, proximally and distally, to which a conventional hand-sewn anastomosis can be performed. This minimizes the risk of proximal endoleak, eliminates residual dissections in and beyond the arch, and facilitates manipulations in second-stage operations. Third, the stent graft implanted in the descending aorta is $10-12 \mathrm{~cm}$ in length. It is strong enough to compress the false lumen and obliterate the intimal tear in the arch and proximal descending aorta, as is the case in the majority of type A dissections. Implantation of this elephant trunk is not associated with paraplegia or malperfusion syndromes and promotes false lumen thrombosis for the length of the stent graft and thrombosis of the entire thoracic aortic false lumen. This may obviate the necessity for surgical reintervention in a substantial proportion of these problematic patients. Finally, with inherently high mechanical strength and long-term durability, this stent graft can tolerate the forces of clamping and all manipulations during second-stage operations very well.

\section{Operative Indications}

As our team has gained vast experience since its introduction, the indications of Sun's procedure have evolved considerably [12-17,19-24]. This, in part, may be ascribed to an algorithm dictating the surgical strategies based on our subcategorization of the Stanford system that divides type $\mathrm{A}$ dissections into subtypes according to the aortic root diameter, degree of aortic insufficiency, competency of the sinotubular junction, and the dissection process in the arch and beyond [17].

In our practice, Sun's procedure is chiefly indicated in patients with extensive dilating aortic pathologies (aneurysm and dissection) affecting the ascending aorta, aortic arch, descending aorta, and beyond. Listed below are the most common indications [12-17,19-24]:

(1) type A dissections with the primary entry locating in the arch and descending aorta

(2) type A dissections severely involving the arch vessels

(3) type A dissections with extensive intimal intussusception

(4) Marfan syndrome complicated with type A dissection
(5) thoracic aortic aneurysms involving the ascending aorta, arch, and descending aorta

(6) some type B dissections, such as those involving the arch, or with concomitant cardiac disease requiring surgical treatment; and complications of endovascular repair for type $B$ dissections, including retrograde type A dissection, endoleak, etc.

\section{Clinical Outcomes}

As of January 2013, our team has performed more than 1,000 cases of Sun's procedure, with an in-hospital mortality rate of $4.6 \%$ (6\% in acute cases versus $2 \%$ in chronic cases) and an incidence of second-stage operation of $4 \%$ (most seen in Marfan patients). This is one of the lowest recorded in the literature, three- to four-fold lower than most contemporary reports [25]. Complete thrombus formation around the stented graft is observed in $93 \%$ of patients, extending to the diaphragmatic level in 70\% [16].

At present, nearly 8,000 patients in China have received Sun's procedure as a treatment of aortic dissection or aneurysm (Z.H. Miao, pers. comm., e-mail on February 19, 2013). Cardiac surgeons in South American countries, including Argentina, Brazil, Chile, Ecuador, Uruguay, and Venezuela have successfully treated nearly 200 patients with this procedure. Since 2004, our team has trained over 600 Chinese physicians on Sun's procedure, and spread this technique to more than 70 cardiac centers across China. Between 2009 and 2012, four workshops on Sun's procedure were successfully launched for 117 South American colleagues engaged in the care of patients with aortic disease. Now Sun's procedure is gaining wider acknowledgment in international cardiac surgical community, and "may become the next standard treatment in patients with type $A$ aortic dissection involving repair of the aortic arch" [16].

\section{Acknowledgements}

The authors are deeply indebted to Drs. John A. Elefteriades and Bulat A. Ziganshin for their invaluable assistance in narrating and editing the video of Sun's procedure.

Comment on this Article or Ask a Question 


\section{References}

1. Hirst AE Jr., Johns VJ Jr., Kime SW Jr. Dissecting aneurysm of the aorta: A review of 505 cases. Medicine. 1958;37:217-279.

2. Elefteriades JA, Feldman M. Acute type A aortic dissection: Surgical intervention for all: CON. Cardiol Clin. 2010;28:325-331. 10. 1016/j.ccl.2010.02.010

3. Borst HG, Walterbusch G, Schaps D. Extensive aortic replacement using "elephant trunk" prosthesis. Thorac Cardiovasc Surg. 1983;31:37-40. 10.1055/s-2007-1020290

4. Svensson LG. Rationale and technique for replacement of the ascending aorta, arch, and distal aorta using a modified elephant trunk procedure. J Card Surg. 1992;7:301312. 10.1111/j.1540-8191.1992.tb01020.x

5. Kazui T, Washiyama N, Muhammad BA, Terada H, Yamashita K, Takinami M, et al. Total arch replacement using aortic arch branched grafts with the aid of antegrade selective cerebral perfusion. Ann Thorac Surg. 2000;70:3-8; discussion-9.

6. Karck M, Chavan A, Hagl C, Friedrich $H$, Galanski M, Haverich A. The frozen elephant trunk technique: A new treatment for thoracic aortic aneurysms. J Thorac Cardiovasc Surg. 2003;125:1550-1553. 10.1016/S00225223(03)00045-X

7. Kazui T, Washiyama N, Muhammad BA, Terada $\mathrm{H}$, Yamashita K, Takinami M, et al. Extended total arch replacement for acute type a aortic dissection: Experience with seventy patients. J Thorac Cardiovasc Surg. 2000;119:558-565. 10. 1016/S0022-5223(00)70136-X

8. Svensson LG, Kim KH, Blackstone EH, Alster JM, McCarthy PM, Greenberg RK, et al. Elephant trunk procedure: Newer indications and uses. Ann Thorac Surg. 2004;78:109116; discussion-16.

9. Uchida N, Shibamura H, Katayama A, Sutoh $M$, Kuraoka $M$, Ishihara $H$. Long-term results of the frozen elephant trunk technique for the extensive arteriosclerotic aneurysm. J Thorac Cardiovasc Surg. 2010;139:913-917. 10.1016/j.jtcvs.2009.08.018

10. Kato M, Matsuda T, Kaneko M, Kuratani T, Mizushima T, Seo Y, et al. Outcomes of stentgraft treatment of false lumen in aortic dissection. Circulation. 1998;98:II305-II311; discussion II11-2.
11. Shah A, Coulon $P$, de Chaumaray $T$, Rosario $R$, Khanoyan P, Boukhris M, et al. Novel technique: Staged hybrid surgical and endovascular treatment of acute Type A aortic dissections with aortic arch involvement. J Cardiovasc Surg. 2006; 47:497-502.

12. Liu ZG, Sun LZ, Chang Q, Zhu JM, Dong C, Yu $C T$, et al. Should the "elephant trunk" be skeletonized? Total arch replacement combined with stented elephant trunk implantation for Stanford type A aortic dissection. J Thorac Cardiovasc Surg. 2006;131:107-113. 10.1016/j.jtcvs.2005.09.015

13. Sun LZ, Qi RD, Chang Q, Zhu JM, Liu YM, Yu $\mathrm{CT}$, et al. Is total arch replacement combined with stented elephant trunk implantation justified for patients with chronic Stanford type A aortic dissection? J Thorac Cardiovasc Surg. 2009;138:892-896. 10.1016/j.jtcvs.2009. 02.041

14. Sun LZ, Qi RD, Chang Q, Zhu JM, Liu YM, Yu $\mathrm{CT}$, et al. Surgery for acute type A dissection using total arch replacement combined with stented elephant trunk implantation: Experience with 107 patients. J Thorac Cardiovasc Surg. 2009;138:1358-1362. 10.1016/j. jtcvs.2009.04.017

15. Sun LZ, Qi R, Chang Q, Zhu JM, Liu YM, Yu CT, et al. Surgery for acute type $A$ dissection with the tear in the descending aorta using a stented elephant trunk procedure. Ann Thorac Surg. 2009;87:1177-1180. 10.1016/j.athoracsur. 2009.01.042

16. Sun LZ, Qi R, Zhu JM, Liu YM, Zheng J. Total arch replacement combined with stented elephant trunk implantation: A new "standard" therapy for type a dissection involving repair of the aortic arch? Circulation. 2011;123:971978.

17. Sun LZ, Qi R, Zhu JM, Liu YM, Chang Q, Zheng J. Repair of acute type A dissection: Our experiences and results. Ann Thorac Surg. 2011;91: 1147-1152. 10.1016/j.athoracsur.2010.12.005

18. Zhu XD. Preface. In: Sun LZ, Zhu JM, Liu YM, Fan ZM, Huang LJ, eds. Surgery of the Aorta. 1st ed. Beijing: People's Medical Publishing House. 2012;5.

19. Sun LZ, Qi R, Chang Q, Zhu JM, Liu YM, Yu $C T$, et al. Surgery for Marfan patients with acute type $\mathrm{A}$ dissection using a stented ele- phant trunk procedure. Ann Thorac Surg. 2008;86:1821-1825. 10.1016/j.athoracsur. 2008.08.026

20. Li B, Sun LZ, Chang Q, Zhu JM, Yu CT, Liu YM, et al. Total arch replacement with stented elephant trunk technique: A proposed treatment for complicated Stanford type B aortic dissection. J Card Surg. 2009;24:704-709. 10. 1111/j.1540-8191.2009.00925.x

21. Sun LZ, Zhao X, Chang Q, Zhu JM, Liu YM, Yu $\mathrm{CT}$, et al. Repair of chronic type $\mathrm{B}$ dissection with aortic arch involvement using a stented elephant trunk procedure. Ann Thorac Surg. 2010;90:95-100. 10.1016/j.athoracsur.2010. 03.048

22. Sun LZ, Li M, Zhu JM, Liu YM, Chang Q, Zheng J, Qi R. Surgery for patients with Marfan syndrome with type $A$ dissection involving the aortic arch using total arch replacement combined with stented elephant trunk implantation: The acute versus the chronic. J Thorac Cardiovasc Surg. 2011;142:e85-491. 10.1016/j. jtcvs.2011.01.038

23. Zhu JM, Cheng LJ, Liu YM, Zheng J, Qiao ZY, $\mathrm{Li} \mathrm{CN}$, et al. One-stage repair for Stanford type B aortic dissection concomitant with cardiac diseases: Open stented elephant trunk technique combined with cardiac operation. Thorac Cardiovasc Surg. 2012;60:1116. $10.1055 / \mathrm{s}-0031-1298068$

24. Zhao HP, Zhu JM, Ma WG, Zheng J, Liu YM, Sun LZ. Total arch replacement with stented elephant trunk technique for acute type B aortic dissection involving the aortic arch. Ann Thorac Surg. 2012;93:1517-1522. 10.1016/j.athoracsur.2012.01.013

25. Girardi LN. Invited commentary. Ann Thorac Surg. 2011;91:1153. 10.1016/j.athoracsur. 2011.01.004

Cite this article as: Ma WG, Zheng J, Liu YM, Zhu JM, Sun LZ. Dr. Sun's Procedure for Type A Aortic Dissection: Total Arch Replacement Using Tetrafurcate Graft With Stented Elephant Trunk Implantation. Aorta 2013;1(1):59-64.DOI:http://dx.doi.org/ 10.12945/j.aorta.2013.13.015

\section{EDITOR'S COMMENTS AND QUESTIONS}

The Sun's technique described in the paper by Ma and colleagues reflects an innovative and imaginative enhancement of surgical options for the dissected (or aneurysmal) ascending aorta and arch. This procedure, described clearly in this article by the originators, is becoming increasingly widely applied globally.

\section{Questions}

1. Congratulations on this important, innovative addition to our surgical armamentarium. The 
list of potential indications you provide encompasses almost all ascending and arch pathologies. Do you do a simple ascending replacement for any patients?

In our practice, we subcategorize type A dissections into simple and complex subtypes. Complex subtype refers to either of the following conditions: 1) the primary tear is located in the transverse arch or descending aorta; 2) dilatation of the arch or distal aorta (diameter $>50 \mathrm{~mm}$ ); 3) involvement or dilation of the arch vessels; 4) Marfan syndrome. We would recommend the Sun's procedure for patients with complex type A dissections. Other conditions belong to the simple subtype, which is treated with root or ascending replacement procedures. A detailed description of our subcategorization system was published in the April issue of the Annals of Thoracic Surgery in 2011 [Repair of acute type A dissection: Our experiences and results. Ann Thorac Surg. 2011;91(4): 1147-1152].

In cases when we do simple ascending aortic replacements for patients with type A dissections, the selection criteria should include the following conditions simultaneously: 1) the tear is located in the ascending aorta; 2) the arch vessels are not involved; 3) the aortic arch is not dilated; and 4) non-Marfan etiology.

2. For a type A dissection in a non-Marfan patient with the tear located in the ascending aorta, do you still perform your more extensive procedure?

Based on the reasoning stated above, for a type $A$ dissection in a non-Marfan patient with the tear located in the ascending aorta, we will not perform this more extensive procedure. Instead, we will perform an ascending aortic replacement as long as the arch is not dilated. 